\title{
ESTVDIO (1913-1920): Presència i projecció de la cultura catalana en una revista barcelonina d'expressió castellana ${ }^{1}$
}

\section{ESTVDIO (1913-1920): Presence and Projection of the Cata- lan Culture in a Spanish Language Magazine of Barcelona}

DOlORS MADREnAS Tinoco

\author{
(DdE - Barcelona) \\ dolorsmadrenas@gmail.com \\ JOAN M. RIBERA LLOPIS \\ (UCM) \\ jumriber@filol.ucm.es \\ Recibido: abril de 2015. Aceptado: mayo de 2016
}

\begin{abstract}
Resum: Presentació de la revista Estvdio i rellevància del seu abast en l'estudi de les relacions entre les tradicions ibèriques. Ordenació dels seus continguts filològicament $\mathrm{i}$ culturalment catalans.
\end{abstract}

Mots clau: Cultura, llengua i literatura catalanes contemporànies. Relacions peninsulars.

\footnotetext{
1 Una primer escorç d'aquest treball fou presentat al XVIè Col-loqui Internacional de Llengua i Literatura Catalanes (AILLC - USAL, 1-6 juliol de l'any 2012). Forma part d'una recerca plantejada conjuntament amb la Dra. M. ${ }^{a}$ V. Navas Sánches-Élez (UCM) sobre la presència a la revista Estvdio de les cultures i literatures peninsulars no castellanes. Sobre les col-laboracions complementàries ja publicades, veure: Navas Sánchez-Élez, M. ${ }^{a}$ V., «Estvdio (1913-1920): las letras portuguesas en una revista catalana de expresión castellana», Congreso Internacional 'Las relaciones entre las literaturas ibéricas' (Universitat Pompeu Fabra, Barcelona, 18-20 juny de l'any 2009), dins F. Lafarga, L. Pegenaute i E. Gallén (eds.), Interacciones entre las literaturas ibéricas. Relaciones literarias en el ámbito hispánico: traducción, literatura y cultura, Berna, Peter Lang, 2011, vol. III, pp. 315-329; Navas Sánchez-Élez, M. ${ }^{a}$ V., Ribera Llopis, J. M., «Estvdio (19131920): recepción de la cultura gallega en una revista catalana de expresión castellana», X Congreso Internacional da Asociación de Estudos Galegos (Cardiff University, UK, 12-14 setembre de l'any 2012), dins Revista de Lenguas y Literaturas Catalana, Gallega y Vasca, UNED, n. ${ }^{\circ} 18$, 2013, pp. 249-260. En el present lliurament, les referències bibliogràfiques al material extret d' $E s$ tvdio es donen precedides de la inicial $E$, seguida d'any, número de volum i pàgines.
} 


\begin{abstract}
Presentation of the Estvdio review and relevance of its significance in the study of relations between the Iberian traditions. Ordenation of its philologically and culturally Catalan contents.
\end{abstract}

Key words: Contemporary Catalan culture, language and literature. Peninsular relations.

I. Revista de manera assíduament citadada en el camp de la Filologia perquè en les seves pàgines, entre el darrer quadrimestre de l'any $1914 \mathrm{i}$ el primer semestre del 1915, aparegueren els articles de Lluís Nicolau d'Olwer (1888$1961)^{2}$-punt de partida dels volums Literatura Catalana. Perspectiva general (1917) i Resum de Literatura Catalana (1927)-, és exponent de la magnífica tradició assolida per les publicacions periòdiques ibériques des de mitjans del vuit-cents fins als anys trenta del nou-cents. Document només concretament aprofitat com a font d'estudi de les relacions entre les cultures de la nostra Península -sobre l'entrada del pensament i de l'obra de contemporanis portuguesos en l'àmbit cultural català (Cerdà 2000: 529); quant a la tasca pro-lusitanista del Cercle Maristany, tant el seu context com referències concretes (Harrington 2002; 2003: 178); pel que fa a la comprovació de relacions literàries i a l'aparició de traduccions catalanes, després constatades en aquestes mateixes pàgines (Ribera 2007: 202-203, 264-265; Madrenas + Navas + Ribera 20072008: 114-118); i a propòsit de la densa i extensa presència de la cultura i de les lletres portugueses en els seus volums (Navas 2011)-, Estvdio fou un dels òrgans d'expressió de la Societat d'Estudis Econòmics (Barcelona, f. 1907). Amb seguretat va ésser el seu mitjà més culturalment divulgatiu -no tant pel seu registre sinó per la varietat dels seus continguts: societat, economia, ciència, geografia física i humana, també història, art, lingüística i literatura- i ventall de matèries diferents del grau d'especialització d'una altra revista de l'entitat, La Economía Nacional (1909) que, d'acord amb el seu encapçalament, perseguia la implantació des de Catalunya i en la societat espanyola dels corrents d'estudi de la ciència econòmica amb circulació continental, entesos com a eina de progrés.

L'esmentada Societat d'Estudis Econòmics sí compta amb una extensa monografia per part de M. Sellés i Quintana (2002) que, lògicament, abasta el perfil dels seus membres i la trajectòria de les seves publicacions; i una puntual aproximació mitjançant les aportacions a la redacció d'Estvdio i a alguns dels seus col-laboradors, d'acord amb les notes de M. ${ }^{a}$ V. Navas (2011). D'aquestes fonts es desprèn la reconeixença d'un projecte i l'actuació d'uns intel-lectuals i alhora professionals gens estranys a la proposta noucentista; això, en un entorn amb clara delimitació política i de repercussió catalanista, crescut entre la creació de Solidaritat Catalana (1906) i la sotragada marcada per la Dictadura de Primo de Rivera (1923-1930) (Sellés Quintana 2002: 15-19, 33-76, 79-83, 97-102). Si per aquesta font sabem que l'activitat del seus membres no fou aliena a la consecució de la Mancomunitat Catalana (1914-1925), també podrem recordar que, en la gestació de la Societat

2 Ll. Nicolau d'Olwer, «Introducción al estudio de la literatura catalana», E, 1914, 21: 328351; 1914, 22: 1-15; 1914, 23: 177-195; 1914, 24: 355-369; 1915, 25: 2-27; 1915, 26: 297-315; 1915, 27: 471-491; 1915, 28: 1-24; 1915, 29: 185-196; 1915, 30: 377-407. 
d'Estudis Econòmics, hi figurarien els Estudis Universitaris Catalans (Sellés Quintana 2002: 21-24), fundats en 1903 i entre la programació dels quals es van dictar les lliçons sobre literatura que l'esmentat Lluís Nicolau d'Olwer editaria finalment a Estvdio. Aquest és un condensat escorç d'un cicle històric, exponent d'un delimitat fons programàtic i d'una eficient xarxa de personalitats implicades, aplegades moltes d'elles en òrgans d'expressió com el que ens ocupa.

Pel que fa a la redacció d'Estvdio, les línies del seu editorial inaugural o «Lector» i del text que celebra el primer aniversari o «Nuestra Revista. Gratitud» insisteixen en la pluralitat social, política i cultural dels seus col-laboradors, en el seu amor a la cultura i la seva voluntat d'estudi i de recerca, i en el seu desig, si no de moviment propi, sí de «...llegar a condensar en Estvdio el movimiento intelectual del mundo culto (...), los más importantes aspectos de la producción científica contemporánea» $(E, 1913,12: 314)$ : per tant, en la seva configuració com a grup intermediari i difusor d'una proposta de renovellament científic i cultural. I encara que amb projecció estatal, però també en i des de Catalunya, Guillermo Graell (1847-1927), president honorífic de la SEE, autor de l'inicial article del número primer de la revista, «La acción económica», i davant carències generals, adverteix com «Los catalanes, en general no podemos permanecer inactivos, pues siempre tenemos problemas por resolver que nos espolean en lo más vivo» $(E, 1913,1: 13-14)$, i assenyala l'assumpte de les comunicacions i de la repartició territorial i la qüestió social com a punts que cal afrontar directament; i quan, tot seguit, Manuel de Montoliu (1877-1961) acara els afanys de renovació de la Filologia Romànica en «La Geografía Lingüística», afirma que el país romànic amb major retard en la constitució dels urgents Atles lingüístics és Espanya, malgrat poder destacar la tasca del desenvolupament a favor de la Romanística per part dels catalans -des del «gran Milà» als «proyectos grandiosos» de l'IEC $(E, 1913,1: 29)-$, tot iaixí ens manca un atles peninsular que delimitaria la geografia del català en correspondència amb la resta de la geografia lingüística peninsular; i si en unes de les «Notas bibliográficas» d'aquest mateix any inaugural i amb la signatura de J. B. és ressenya el volum de Cebrià Montoliu (1873-1923) Walt Withman, l'home i sa tasca, significant l'autor nord-americà pels seus valors socials i democràtics, s'acaba per destacar: «Cataluña por su carácter industrial, por su fondo democrático necesitaba, más que otro país, un estudio de este poeta en toda su amplitud.» $(E, 1913,11: 311)^{3}$. Cal, doncs, abastar Estvdio com a publicació d'ampli contingut cultural, de perfil regeneracionista, il-lustradament progressista $\mathrm{o}$, almenys, renovador i amb horitzó estatal però des de la consciència de la particularitat i la defensa de la identitat catalana.

$\mathrm{Al}$ respecte i pel que fa a l'ús del castellà com a mitjà d'expressió, cal entendre-ho com a opció compartida amb altres òrgans d'expressió nadius, potser dins una pervivència de la tradició catalanista de caire regionalista-pactista, diferenciada ja coetàniament del vessant separatista, encara que des de les seves pàgines

${ }^{3}$ La Redacción, «Lector», E, 1913, 1: portada; La Redacción, «Nuestra Revista. Gratitud», $E$, 1913, 12: 313-314; G. Graell, «La acción económica», E, 1913, 1: 1-14; M. de Montoliu, «La geografía Lingüística», E, 1913, 4: 76-98; J. B. «Montoliu, Cebrià, Walt Withman, l'home i sa tasca», E, 1913, 11:310-311. 
no s'evita, com per exemple en la ressenya a un article de Luis Icaza (s. f.), el nom d'Enric Prat de la Riba i la seva definició de nació $(E, 1918,74: 256)^{4}$. A més, el bilingüisme de molts dels seus col-laboradors catalans, amb obra en català al marge del volums de la revista, els allunya d'un posicionament espanyolista-castellanitzant; així com l'atenció explícita des d'Estvdio a bibliografia en català, a figures i fets de la història catalana. Valgui per ara la següent expressió sobre la identitat lingüística catalana, que llegim en la ressenya d'una bibliografia sobre Jacint Verdaguer: «la lengua literaria que hoy usamos» $(E, 1914,13$ : $150)^{5}$. Tan sols afegirem la constatació de textos en llengua catalana quan es transcriuen versos de Withman segons la traducció ja anotada $(E, 1913,11: 311)$ o a propòsit del cançoner estudiantil dels universitaris de Cervera $(E, 1913,11$ : 180). A partir d'aquesta aproximació a Estvdio, passem a endinsar-nos en els seus criteris, ordenant els materials publicats on el discurs s'estableix fonamentalment sobre o des de referents catalans que, així, es projecten sobre l'espectre estatal espanyol i, amb l'ús del castellà, assoleixen una difusió més àmplia.

II. A propòsit del que podríem encarar com a comprensió i significació de les arrels i dels pilars que ens proven origen i vigència d'un sistema cultural propi, destacarem certs components evidenciats a Estvdio. En aquest nivell compositiu de la revista, potser caldria fer una excepció i advertir com s'insereix en una comprensió coetània i humanista de la cultura. A favor d'això i a tall d'exemple, ens valdran algunes mostres de l'assagisme de signatures com Santiago Valentí Camp (1875-1934), José Comas Solà (1868-1937), Enrique Massaguer (trad. de títols lit. constatats entre 1903 i 1913) o Rafael Campalans (1887-1933), en abordar qüestions d'ordre social com l'antiesclavisme i el tràfic de blanques, la consciència crítica del present històric o la necessitat del desenvolupament científic, tot raonant-se des de la filosofia científica o cercant nous fonaments ${ }^{6}$. En aquest marc -reforçat davant la sotragada de la I Guerra Europea, motiu de la publicació d'un manifest amb sentiment europeista, signat per diverses personalitats i institucions i afirmant la «creencia irreductible en la unidad moral de Europa» $(E, 1915,25: 118)^{7}$-, l'espectre espanyol i la presència de la cultura nadiua en aquest conjunt es presenta, per Santiago Valentí Camp, destacant entre altres positives excepcions, la constància d'una producció industrial localitzada a Catalunya i part del Llevant i la realitat urbana de Barcelona com a objectivitats aïllades, allí on, i pel contrari,

... la fisonomía de España no ha experimentado la transformación rápida y profunda que Francia e Italia, las cuales en las últimas cinco décadas han mul-

4 F. de A. R., «El principio de las nacionalidades, por Luis Icaza», E, 1919, 74: 254-260.

5 M. de M., «Bibliografía de Jacinto Verdaguer, por Robert Dubois», E, 1914, 13: 149-150.

6 S. Valentí Camp, «Instituciones de cultura social. El tráfico de esclavos y la Asociación antiesclavista y de protección de indígenas», E, 1914, 14: 199-227; J. Comas Solá, «Ensayos de Filosofía Científica», E, 1914, 15: 388-394, i 16: 75-85, i 17: 309-321; S. Valentí Camp, «Indagaciones y lecturas. Evolución y revolución», E, 1914, 16: 52-61; E. Massaguer, «Instituciones de cultura social. Asociación Internacional para la represión de la trata de blancas», E, 1914, 19: 42-55; R. Campalans, «Sobre los fundamentos de la Termodinámica», E, 1914, 18: 422-442.

7 S.f., «En torno a la Guerra. Manifiesto de los amigos de la unidad moral de Europa», E, 1915, 25: 118-120. 
tiplicado su esfuerzo para acrecentar, no sólo su potencia económica, si que también su prestigio, en todos los órdenes, desde el agrario hasta el intelectual (E, 1914, 15: 427).

Ens trobem, certament, davant una comprensió global d' «el pueblo español», però amb la reconeixença d'uns «... elementos constitutivos de la Península» que es manifesten com a diferències d'ordre ètnic d'abast etnològic, lingüístic, folklòric, artístic o antropològic, d'acord amb Juan Dantín Cereceda (1881-1943) ( $E, 1913,1: 77)$. Un conjunt amb diferències, doncs, el panorama del qual no s'evita abastar críticament respecte de cadascuna de les parts integrants; com quan Francisco de A. Rodón (s. f.) adverteix, en al-lusió a l'estat de les coses i a la capacitat de resposta espanyola:

... ni el pueblo español, ni su florón Cataluña, consiguen ocupar el lugar que acreditan en la economía mundial. Llevamos todos un retraso de medio siglo [...]. Somos inorgánicos aún, y ni divisamos, de lejos que está, aquella concentración de la industria que forma de sus ramas sectores compactos de un centro único, en que se condensan todas las empresas nacionales. Nos falta abrevar nuestro trabajo en la ciencia [...]. Y faltan, además, grandes técnicos en las fábricas, bancos industriales en las ciudades, sindicatos de exportación en las metrópolis y un ideal económico en las almas. ¿Cómo improvisar esto? Cataluña pudo hacer algo, pero no supo poner sus aspiraciones más allá del balance inmediato, y España entera va perdiendo, a medida que la guerra agota a los más fuertes la ocasión más venturosa que le brindó la historia $(E, 1916,47:$ 196-197).

Criteri, el de Francisco de A. Rodón, que pot merèixer altres expectatives, com les de Guillermo Graell, plantejades amb les següents paraules:

Hoy la acción política está moldeada por las necesidades que ha creado la civilización, y en consecuencia, para satisfacerlas, por la acción económica, y ¿quién tiene en España estos moldes más que Cataluña? Las naciones todas están en la esfera política definitivamente constituidas, y las divisiones de aquí por idealismos irrealizables, formalistas, sentimentales, son ya desconocidas fuera de nuestro reino. Son otros problemas muy distintos y de mucha mayor trascendencia los que preocupan a los que se dedican a la vida pública. Estas son las cuestiones que reclaman la intervención de Cataluña, y que deben merecer la atención de toda España... $(E, 1913,5: 155)^{8}$.

Potser com a arrel de la parcial excepcionalitat catalana, com a substrat del que assenyalarem en l'apartat següent sobre aspectes de tipus social i d'abast econòmic, Estvdio remet a la història de la vida universitària catalana, no

8 S. Valentí Camp, «Indagaciones y lecturas. La acción propulsora de la prensa. V», E, 1914, 15: 426-445; J. Dantín Cereceda, «El hombre y el relieve terrestre de la Península», E, 1913, 1: 61-78; F. de A. Rodón, «Intimidades de la potencia industrial de Cataluña», E, 1916: 47: 184-197; G. Graell, «Nuestra acción política», E, 1913, 5: 145-157; 
exempta d'experiències conflictives; també a les fonts i a la bibliografia històriques de territoris i institucions pròpies, de senyoratges nadius i d'episodis remarcables ${ }^{9}$. I, per igual, al protagonisme de personatges i llinatges catalans en el desenvolupament intel-lectual espanyol, a propòsit dels que, en introduir a l'historiador català Salvador Sanpere y Miquel (1840-1915), se'ns diu que

... laboraron con denuedo por el triunfo y el afianzamiento de la libertad en el orden político y que en la esfera de la cultura trabajaron sin sentir jamás el desaliento, con el noble empeño de contribuir al resurgimiento de las letras, de la historia, de la crítica y, aunque en menor medida, de la filosofía, y en general de cuanto representase una intensificación de la actividad espiritual entre nosotros $(E, 1915,35: 223)^{10}$.

Així es destaca la família Ibarra de tipògrafs de Cervera (s. XVIII), el filòsof vuit-centista Pedro Sala o el susdit historiador, cadascun d'ells i sempre entre noms i dades complementàries que confirmen «... el desenvolvimiento de la personalidad colectiva de Cataluña en el paso de los tiempos.» $(E, 1915,35$ : $223)^{11}$. En aquest sentit, el d'alguns perfils destacats i els seus components ideològics o de classe -és el cas de Josep Torras i Bages o el de certs aristòcrats o la pròpia aristocràcia que «... han contribuido al resurgimiento de Cataluña y se han hecho acreedores a la gratitud de sus conciudadanos...» $(E, 1913,61$ : 62)-, cal interrogar-se si aquesta dada expressa el fons classista de la SEE i de la redacció de la seva revista, si és indici del conservadurisme il-lustrat del grup rector i de la redacció. ${ }^{12}$ En tot cas, això mateix no anul·la l'afany de progrés revisionista ni el component d'afirmació catalana. A tall de mostra, Estvdio no sols celebra i notifica la convocatòria del II Congreso de Historia de la Corona de Aragón, continuació d'una primera convocatoria del congrés de 1908, en les sessions del qual «... predominó el espíritu catalán» $(E, 1920,92: 219)$; a més, i davant el descobriment paleogràfic d'un document sicilià que passaria a ésser el primer document en paper, es reclama per part de la Real Academia de la

9 M. Rubió y Borrás, «El estudiante en la Universidad de Cervera», E, 1913, 11: 164-183, $\mathrm{i}$ «Motines de estudiantes en la Universidad de Barcelona en los siglos XVI, XVII y XVIII», $E$, 1914, 13: 31-57; F. de A. Rodón, «Las fuentes narrativas de la historia de Tarragona en la Edad Antigua», E, 1914, 19: 83-98, i 1914, 21: 397-416; F. de Camp, «La administración napoleónica en Cataluña. 1808-1814», E, 1914, 20: 214-231; F. Camp, «Memoria del Ayuntamiento de Barcelona a las Cortes de Bayona sobre las aspiraciones de Cataluña», E, 1916, 44: 268-272; R. del Arco. «D. Pedro Antonio de Aragón y el Real Monasterio de Poblet», E, 1916, 46: 26-40; F. de A. Rodón, «El territorio de 'Scala Dei' antes del señorío de los cartujos», E, 1918, 64: 12-33; G. Fernández Díez, «Memorial del Ayuntamiento y Junta de Comercio de Barcelona al emperador Napoleón en 1811», E, 1918, 64: 49-61; M. Beguer Piñol, «El antiguo señorío de Pauls y la familia Despuig», E, 1919, 74: 210-215; F. Camp, «Documentos inéditos de la administración civil napoleónica de Cataluña», E, 1920, 94: 24-37

10 S. Valentí Camp, «Un historiador catalán. Salvador Sanpere y Miquel», E, 1915, 35: 223-230.

11 M. Rubió y Borrás, «La imprenta en España. Los Ibarra en Cervera», E, 1913, 5: 176-184; S. Valentí Camp, «Indagaciones y lecturas. Un filósofo ignorado», $E, 1915,32: 212-234$; S. Valentí Camp, «Una gran figura del catolicismo español. José Torrás y Bages», $E$, 1916, 39: 345-357.

12 J. Pablo Rivas, «La aristocracia catalana», E, 1913, 61: 62-72, i 1918, 66: 394-404; C. V., «Don Ignacio Estrada Ballbé», E, 1919, 80: 245. 
Historia, de l'Institut d'Estudis Catalans i de la Junta para Ampliación de Estudios que es comprovi la veracitat de la descoberta que trauria tal lloc d'honor a un Registre de 1237 i de Jaume I (ACA) ${ }^{13}$.

Es tracta, doncs, d'un entramat de diversos continguts que cobren una especial rellevància, conjunt a favor del qual és complementàriament significatiu el tipus de bibliografia ressenyada -bona part d'ella, editada en català-, d'acord amb el que queda mostrat a peu de pàgina, $i$ que aborda els més diversos camps d'estudi, des de l'arqueologia a la ictiología, l'espeleologia o l'aeronàutica ${ }^{14}$.

13 S. f., «Ecos y notas. El primer documento en papel...», E, 1920, 91: 157-158; A. Gascón de Gotor, «II Congreso de Historia de la Corona de Aragón», E, 92: 219-237;

${ }^{14}$ F. de A. R., «Cosme Parpal, La Isla de Menorca en tiempo de Felipe II. Antonio Rubió y Lluch, La escuela histórica catalana», E, 1914, 14: 327-329; A. Arnau Arigas, «Agustín M. a Gibert, Fauna ictiològica de Catalaunya. Catàlec rahonat dels peixos observats en el litoral y en les aygues dolces catalanes», E, 1914, 15: 488-489; F. de A R., «José Elías de Molins, Los riegos en la provincia de Tarragona», E, 1914, 15: 497-498; M. R., «Cámara de Comercio y Navegación de Barcelona», E, 1914, 15, 498-499; F. de A. R., «Maximilien Sorre, Les Pyrenées Méditerranéennes. Etude de Geographie biologique», E, 1914, 16: 164-165; F. de A. R., «V. C. Scott O'Connor, Travels in the Pyrenees, including Andorra and the coast from Barcelona to Carcassonne», E, 1914, 18: 559560; L., «César August Torras, Pirineu català. Vall de Ribes. Altes valls del Freser», E, 1914, 21: 487; M. M., «R. d'Abadal y Vinyals, «Les 'Partidas' a Catalunya», E, 1915, 27: 649-650; S. V. C., «Isidre Lloret, Dret Orgànic Municipal», E, 1915, 30: 517-518; F. de A. R., «Carlos Riba y García, El Consejo supremo de Aragón en el reinado de Felipe II», E, 1915, 31: 129-131; F. de A. R., «Miguel González y Sugrañes, Contribució a la Història dels antics gremis dels Arts y Oficis de la ciutat de Barcelona. I», E 1915, 31: 131-133; F. de A. R., «Manuel Rubio y Borrás, Historia de la Real y Pontificia Universidad de Cervera. I», E, 1915. 35: 323-326; S. Valentí Camp, «F. Culí y Verdaguer, Las Mancomunidades Provinciales», E, 1916, 43: 176-177; E. H. del V., «Pío Font Quer, Sobre la flora de la Selva», E, 1916, 44: 355; F. de A. R., «Lorenzo Sallent y Gotés, Pbro., Història documentada del poble i parroquia de Santa Maria de Vallvidrera», E, 1916, 48: 506507; F. de A. R., «Institut d'Estudis Catalans, Anuari MCMXIII-XIV. Any V», E, 1917, 51: 529531; F. de A. R., «Luis del Arco y Muñoz, La prensa periódica en España durante la guerra civil de la Independencia (1808-1814)», E, 1917, 51, 608-609; F. de A. R., Ángel del Arco, La imprenta en Tarragona. Apuntes para su historia y bibliografía», E, 1917, 51: 609-610; F. de A. R., «Fidel de Moragas y Rodés, Catàleg dels llibres, pergamins i documents antics de l'Arxiu municipal de la ciutat de Valls», E, 1917, 51: 611; F. de A. R., «F. Carreras y Artau, Arxiu d'Etnografia $i$ Folklore de Catalunya. Estudis i materials», 1917, 51: 612-613; Z., «Aurelio Ras, La orientación de España», E,1917, 51: 643-646; F. de A. R, «Gabriel M. Vergara, Divisiones tradicionales del territorio español», E, 1917, 52: 155-158; F. de A. R., «Manuel Rubio y Borrás, Historia de la Real y Pontificia Universidad de Cervera. II», E, 1917, 53: 317-320; F. de A. R., «J. Givanel y Mas, Catàleg de la Col-lecció cervantina Bonsoms», E, 1917, 53: 320-321; A. A., «J. LLuzar Rodrigo, Los buques submarinos actuales», E, 1917, 54: 506-509; F. de A. R., «F. Carreras y Candi, Geografía general de Catalunya. La ciutat de Barcelona», E, 1917, 54: 510-512; F. de A. R., «Antonio Agustín, Diàlegs de les armes i llinatges de la noblesa d'Espanya», E, 1918, 61: 186188; F. de A. R., «Francisco Monsalvatje y Fossas, Los Condes de Ampurias vindicados», E, 1918, 62: 364-365; C. M., «Pau M. Turull, La Societat de les Nacions, la Moral Internacionalista i Catalunya», E, 1918, 63: 564; F. de A. R., «Puig Pujadas, Vida d'heroi. Narcís Monturiol, inventor de la navegació submarina», E, 1918, 65: 323-324; F. de A. R., «Luis Redonet y López-Dóriga, Los 'Usatjes' de Barcelona», E, 1918, 68: 311; F. de A. R., «P. Bosch y Gimpera, La últimas investigaciones arqueológicas en el Bajo Aragón y los problemas ibéricos del Ebro y de Celtiberia», E, 1918, 69: 503; F. de A. R., «Analecta Montserratensia. Volum I. Any 1917», E, 1918, 71: 343-344; 
Respecte d'aquest últim llindar per conèixer el material català o sobre cultura catalana projectat des de la revista, s'han de tenir presents per igual les seccions «Revista de revistas» $\mathrm{i}$ «Libros recientes», amb nombroses entrades autòctones. Aquesta advertència ens ha de valer també per als apartats següents, allà on deixarem constància del respectiu material ressenyat.

III. Lligats amb aquest plantejament de fons, hi ha altres continguts que podem entendre d'abast social, en ocasions concretats en les vessants econòmica, geográfica o administrativa. Així, Guillermo Graell planteja la relació entre geografia, ordenació del territori, obres públiques i economia i benestar de la població catalana $\mathrm{o}$, potser, del seu impediment ${ }^{15}$. Si el factor geogràfic és relacionat amb la situació espanyola des d'una vessant metafísica i antropològica, passant pels tòpics sobre Madrid / Barcelona (classes paràsites / població treballadora, centralització / autonomisme) per Emilio H. del Villar (1871-1951), Francisco de A. Rodón torna, des de l'estudi històric més objectiu, sobre la divisió administrativa de Catalunya com a generadora d'un problema nacional, confiant en la Mancomunitat com a via per a millorar l'estat social i, fonamentalment, si es prenen les ciutats, no les comarques, com a «punto de partida»: «En los hombros robustos de ellas debe tener asiento cuanto nuevo se instaure, su espíritu ha de alentarlo [...]. Y con ellas, y sobre ellas, Barcelona, eje de Cataluña, arco triunfal tendido a los pensamientos renovadores, corazón grande que recoge toda la sangre nacional para devolverla a los órganos y a la periferia oxigenada y pura.» $(E, 1913,12: 386)^{16}$.

Amb aquest criteri urbanita prevalent, se celebra a partir de l'any 1916 el projecte proper de l'Exposició de Barcelona; el creixement a la ciutat i amb ideologia feminista d'una infraestructura favorable a «Emancipar la mujer, ele-

F. de A. R., «Miguel González y Sugrañes, Contribució a la història dels antics gremis dels arts $i$ oficis de la ciutat de Barcelona. II», E, 1919, 73: 149-150; F. de A. R., «Juan Ferraté, Espeleologia de les comarques tarragonines», E, 1919, 73: 157-158; F. de A. R., «Daniel Girona y Llagostera, Martí, Rei de Sicília, primogènit d'Aragó», E, 1919, 75: 445-446; F. de A. R., «M. Rossell y Vilá, Importancia de la ganadería en Cataluña y estudio zootécnico de algunas de sus comarcas», E, 1919, 80: 349-350; F. de A. R., «Francisco Monsalvatje y Fossa, Los Castillos del Condado de Besalú», E, 1919, 81: 540-541; F. de A. R., «Federico Gómez Llueca, El mioceno marino de Muro (Mallorca), E, 1919, 83: 287; F. de A. R., «Analecta Montserratensia. Volum II, any 1918», E, 1919, 83: 290; M. C. B., «F. Bosch Gimpera, Prehistoria catalana», E, 1920, 85-86: 217; M. C. B., «Francisco de Moncada, Empresas y victorias alcanzadas por el valor de pocos catalanes y aragoneses contra los imperios de turcos y griegos», E, 1920, 85-86: 221-222; J. F. R., «Ángel Ruiz y Pablo, Historia de la Real junta particular de Comercio de Barcelona (1758 a 1847)», E, 1920, 93: 498; F. de A. R., «Dom Butler, La vida monàstica segons San Benet», E, 1920, 93: 499500; A. M. G., «Federico Camp, Contribución al estudio de la administración de Barcelona por los franceses (1808-1814)», E, 1929, 93: 504; F. de A. R., «Fernando de los Ríos Urruti, Vida e instituciones del pueblo de Andorra. Una supervivencia señorial», E, 1920, 95: 285.

15 G. Graell, «La acción económica», $E$, 1913, 1: 3-14; «Orientaciones actuales de España», $E, 1913,3: 292-318$; «Economía individual. Nueva orientación hacia el modo de hacer fortuna», $E, 1914,18: 391-403$.

16 E. H. del Villar, «El factor geográfico y el gran problema de España», E, 1914, 16: 39-51, i 1914, 17: 215-245; F. A. de Rodón, «Problemas nacionales. De la división administrativa de Cataluña», E, 1913, 11: 193-207, i 1913, 12: 371-386. 
varla en el terreno del derecho, colocarla en la vida en una proporcional igualdad de condiciones a las del hombre...» $(E, 1919,75: 336)$; l'atenció a un empadronament cada vegada més perfecte per conèixer millor la pròpia població i a una rigurosa estadística de les classes treballadores barcelonines; altres qüestions com l'escolarització o la higiene, o es monografien les institucions financeres actives en el mitjà català ${ }^{17}$. La qüestió demogràfica i estadística, sempre amb la seva derivació socio-econòmica, és de primer interès en la revista $\mathrm{i}$, en diverses ocasions, les dades catalanes apareixen entre o comparades amb les de la resta d'Espanya, tal i com es pot comprovar en les referències d'aquesta última nota. De manera semblant al que hem assenyalat al final del punt anterior, també cal tenir present, respecte dels anteriors aspectes, el material bibliogràfic ressenyat ${ }^{18}$.

IV. En el camp de la història de l'art, mereixen una puntual atenció les monografies de Benigno Pallol (ref. bibliogràf. constatada de 1893) sobre grans

17 F. de A. Rodón, «La futura Exposición de Barcelona», E, 1916, 39: 345-367; J. Comorera, «En torno del problema nacional», E, 1916, 40: 18-38; E. Massaguer, «Instituciones de cultura social. El Instituto Internacional de Estadística y los Congresos de Higiene y Demografía», E, 1917, 51: 390-406; R. F. de Castro, «El contrato de trabajo y el código civil», E, 1917, 54: 367-387; S. Valentí Camp, «Vida social española. La población económicamente pasiva y la semiproductiva», $E$, 1917, 59: 207-219, i 1917, 60: 373-389; F. de A. Rodón, «Barcelona y el régimen de exposiciones», E, 1918, 68: 188-204; C. Valdi, «El feminismo en Cataluña. L'InstItut de Cultura i Biblioteca Popular per a la Dona», E, 1919, 75: 334-344; M. Escudé Bartolí, «La población de Barcelona», $E, 1919,76: 28-38$; M. Escudé, «Monografía estadística de las clases trabajadoras de Barcelona», $E$, 1920, 85-86: 2-7, i 1920, 87: 247-276; J. Mas y Roura, «Monografías financieras. El Banco de Barcelona», E, 1920, 90: 440-450; J. Mas y Roura, «Monografías financieras. El Banco de Tarrasa», $E, 1920,93: 409-417$.

18 C. M., «Xavier Calderó, L'habitació popular, cases $i$ hotels pera obrers, empleats i estudiants», E, 1915, 31: 133; S. V. C., «Ignacio Fages de Climent, La Colonia Agrícola de Plegamans. Su organización y funcionamiento», E, 1915, 36: 493-494; F. de A. R., «Miguel Sastre, Las huelgas de Barcelona y sus resultados durante los años 1910 al 1914 ambos inclusive», E, 1916, 39: 480-481; S. V. C., «La cooperación de consumo en Cataluña. Butlletí del Museu Social, año VII, núm. 38», E, 1916, 43: 355-357; S. V. C., «Museu Social de Barcelona. Anuari d'Estadística Social de Catalunya. Año III», E, 1916, 151-152; C. M., «Ayuntamiento de Barcelona. Negociado de Estadística. Anuario Estadístico de la Ciudad de Barcelona. Año XII», E, 1916, 46: 153-154; S. V. C., «José de Montoliu, Los extranjeros ante la Legislación española», E, 1916, 47: 341-342; C. M., «Diputació de Barcelona. Escola de Funcionaris d'Administració Local. Volum de la primera setmana municipal», E, 1917, 54: 512-515; F. de A. R., «P. Gual Villabí, La educación comercial de nuestro pueblo», E, 1917, 60: 526-527; F. de A. R., «Instituto de Reformas Sociales, Estadística de Asociaciones», E, 1917, 60: 529; F. de A. R., «Dirección General del Instituto Geográfico y Estadístico, Estadística de pasajeros por mar. Año 1915», E, 1917, 60: 530-531; F. de A. R., «Instituto de Reformas Sociales, Estadística de los accidentes de trabajo ocurridos en el año 1915, Memoria general de la Inspección de Trabajo correspondiente al año 1915», E, 1917, 60: 531532; F. de A. R., «Ayuntamiento de Barcelona, Anuario estadístico de la ciudad de Barcelona. Año $X I V », E$, 1918, 67: 166; F. de A. R., «Cámara de Comercio y Navegación de Barcelona, Memoria comercial del año 1916», E, 1918, 68: 309-310; F. de A. R., «Juan Comorera, La trágica igorancia española», E, 1919, 80: 346-348; F. de A. R., «Francisco Soler Pérez, Población rural», E, 1919, 80: 348-349; F. de A. R., «[Cámaras de comercio...], Vida económica de la provincia de Tarragona, 1917», E, 1919, 84: 453; J. M. y R., «F. Culí Verdaguer, El Municipi modern», E, 1920, 89: 371-372; M. C. B., «Dr. Maseras Ribera, Maternidad», E, 1920,92: 336. 
figures de la pintura, entre les quals destaquen les dels artistes valencians Juan de Juanes, José de Ribera i Alonso Sánches Coello ${ }^{19}$. Són signatures a propòsit de les quals, en mots del seu estudiós, es pot destriar la consciència d'una tradició artística pròpia, ja que si el darrer «... se halla dentro de la escuela española» i, malgrat el seu origen, «... es, más que exclusivamente valenciano, ampliamente español», no per això «... puede agrupársele de ningún modo dentro de la escuela sevillana, ni menos de la madrileña, que no se había formado entonces.» $(E, 1914,18: 445)$; i, més concretament, el primer cal considerar-lo «fundador de la escuela valenciana», espectre en el qual seguirien Ribalta, Ribera, Espinosa..., «pléyade pictórica» vigent fins al coetani «... pintor del sol, Joaquín Sorolla» (E, 1913, 3: 363, 372).

Entre aquests marges de comprensió de la tradició artística pròpia i en relació o no amb l'espai hispà compartit, els treballs publicats abunden sobre l'art prehistòric, amb referències concretes a descobertes catalanes, oferint la possibilitat d'una ordenació històrica orgànica des dels inicis ${ }^{20}$. L'estudi de l'escultura medieval catalana des del preromàcic fins l'últim període ogival trobarà en els sis lliuraments de Félix Durán (1889-1972) una ben acurada relació ${ }^{21}$. Mentre que els tres extensos lliuraments d'Anselmo Gascón de Gotor (1865-1927) sobre la celebració del Corpus Christi i la consagració artística de les custòdies processionals permeten introduir-se en l'entramat de referents socials, literaris i plàstics de l'esmentada festa, per passar al catàleg d'aquelles peces, entre el patrimoni hispà de les quals es destaquen les catalanes, valencianes i mallorquines que, per cert, resulten preferentment elegides per figurar entre les il-lustrades $^{22}$.

Les pàgines d'Estvdio contemplen també expressions artístiques coetànies com ara l'atenció prestada als aiguaforts dels ex libris modernistes de Ramon Casals y Vernis; o el projecte de jardinería per transformar Montjuïc, notícia que connecta amb el desig de seguir renovellant el model de capitalitat desitja$\mathrm{da}^{23}$. I, fins i tot, es tracten qüestions de museística, al-ludint a un panorama espanyol desolador en aquest aspecte cultural, en el qual i no obstant això es destrien com a excepcions els museus barcelonins; circumstància que, malaura-

19 B. Pallol, «Juan de Juanes», E, 1913, 3: 363-372; «Ribera», E, 1913, 4: 52-64; «Alonso Sánchez Coello», E, 1914, 18: 443-463.

20 J. Dantín Cereceda, «El arte prehistórico en España», E, 1913, 4: 38-50; F. de A. Rodón, «Distribución geográfica de los monumentos primitivos en Cataluña», $E$, 1916, 37: 31-49; P. Planas, S.J., «La prehistoria y protohistoria española a propósito del hallazgo de una ciudad troglodita en Tortosa», $E, 1920,95: 147-168$, i 1920, 96: 307-378.

${ }^{21}$ F. Durán, «La escultura medieval catalana», E, 1918, 67: 18-43; 1918, 69: 346-370; 1919, 77: 192-217; 1919, 78: 342-378; «La escultura en Cataluña en el siglo XV», E, 1920, 87; 276-299; «La escultura decorativa y la imaginería en piedra del último período ojival en Cataluña», $E, 1920$, 92: $192-218$.

22 A. Gascón de Gotor, «El Corpus Christi y las custodias procesionales de España», E, 1916, 42: 392-426.

23 J. C. N. Forestier, «A propósito de los jardines de Montjuich», E, 1920, 88: 57-70; A Gascón de Gotor, «Ramón Casals y Vernis, ex librista catalán», E, 1920, 93: 398-408. 
dament, no es dóna en el Museu Arqueològic de Tarragona ${ }^{24}$. Per tant, un camp aquest de l'art, tractat des de variades arestes, tal i com també documenten les ressenyes bibliogràfique incloses a Estvdio ${ }^{25}$.

V. Finalment, revisarem amb més detall les entrades de contingut filològic, aparegudes en la revista. Si ja està indicada la publicació de la primera part de l'article de Manuel de Montoliu, «La geografía lingüística», ordenem ara la seva continuació, al costat de les actualitzades aportacions sobre fonètica i fonètica experimental per part de Pere Barnils (1882-1933) i encara el treball de Gabriel Cortés (1903-1967) sobre laísmo i leísmo castellans ${ }^{26}$. Ordenem, com en casos anteriors, les ressenyes publicades, aquí sobre matèria lingüística, a propòsit de crestomaties sobre documents catalans antics, una gramàtica de la llengua catalana de Tomás Forteza y Cortés, treballs de dialectologia catalana de Pere Barnils, Antoni Griera o Lluís Fullana, bibliografia estrangera sobre filologia catalana o aportacions de figures nadiues com M. Antoni Alcover, i estudis de lingüística comparada amb exemples catalans ${ }^{27}$.

24 R. del Arco, «Impresiones de Arte. Las obras artísticas y los museos», E, 1918, 70:30-36.

25 M. Rubio Borrás, «Ramón Miquel y Planas, Restauración del arte hispanoárabe en la decoración exterior de los libros», E, 1913, 9: 464; F. de A. R., «Augusto Marguillier, Bibliografía de las obras publicadas sobre Bellas Artes, durante el segundo semestre de 1913», E, 1914, 14: 299-300; P. B. G., «Manuel Cazurro, Los monumentos megalíticos de la provincia de Gerona», E, 1914, 22: 152-153; F. de A. R., «Rodrigo Amador de los Ríos, Reliquias de los musulmanes en Cataluña», E, 1916, 38: 321-323; F. de A. R., «Luis Doménech y Montaner, El Arete en España: Poblet, E, 1916, 43:182; F. de A. R., «Agustín M. ${ }^{a}$ Gubert, Temples pagans de la Tarragona romana», E, 1916, 48: 507; A. Gascón de Gotor, «Manuel Abizanda Broto, Documentos para la Historia Artística y Literaria de Aragón (siglo XVI)», E, 1917, 51: 541-573; F. de A. R., «Fernando de Sagarra, Sigilografia catalana. Inventari, descripció i estudi dels segells de Catalunya», E, 1917, 51: 628-630; F. de A. R., «Francisco Torras $i$ Armengol, amb quaranta reproduccions $i$ una tricromia», E, 1917, 52: 174-175; F. de A. R., «Juan de la Encina, Tendencias del arte español contemporáneo», E, 1917, 55: 171-173; F. de A. R., «Antonio Vives y Escudero, Estudio de arqueología carataginesa. La necrópoli de Ibiza», E, 1917, 60:521-522; F. de A. R., «Dr. Bosch Gimpera, La cultura ibérica», E, 1918, 65: 329; M. R., «Joan Sachs, La pintura francesa moderna hasta el cubismo», E, 1918, 69: 506-508; F. de A. R., «Manuel Escrivá de Romaní, Historia de la cerámica de Alcora», E, 1919, 80: 349-352; A. G. de G., «Foment de les Arts decoratives», E, 1920, 91: 149-150.

26 P. Barnils, «La fonética», E, 1913, 3: 373-382; M. de Montoliu, «La Geografía Lingüística», E, 4: 76-98; P. Barnils, «La fonética experimental», E, 1913, 7: 85-100; G. Nogués, «La cuestión del 'la' i del 'le'», E, 1916, 46: 14-25.

27 B., «Mossèn Pere Pujol, Documents en vulgar dels segles XI, XII \& XIII procedents del bisbat de la Seu d'Urgell», E, 1915, supl. a 25: 204-205; B., «P. Barnils, Die Mundart von Alacant. Beitrag zur Kenntnis des Valencianischen», E, 1915, supl. a 25:207; B., «Rainer Max, Die katalanische Terminologie der Korkstopfenerzeugung», E, 1915, supl. a 25: 207-208; B., «M. de Montoliu, Gramática de la Lengua Castellana», E, 1905, 30: 545; B., «A. Griera, La Frontera Catalana-Aragonesa. Estudi Geogràfic-Lingüístic», E, 1915, 30: 546; M. M., «Tomás Forteza y Cortés, Gramática de la Lengua catalana», E, 1916, 43: 177-178; M. M., «Lluís Fullana, Gramàtica elemental de la Llengua valenciana», E, 1916, 44: 371-372; M. M., «Antoni M. ${ }^{\mathrm{a}}$ Alcover, Pertret per una Bibliografia Filològica de la Llengua Catalana, del temps més antic a 31 de desembre de 1914», E, 1916, 46: 157-158; F. de A. R., «Enrique de Cárcer y de Sobres, Las frases del 'Quijote'. Su exposición, ordenación y comentarios, y su versión a las lenguas francesa, portuguesa, italiana, catalana, inglesa y alemana», E, 1917, 49: 157-158; F. de A. R., «Institut 
$\mathrm{Si}$, pel que fa als estudis literaris, ja hem esmentat la sèrie signada per Lluís Nicolau d'Olwer -fita en la renovació historiogràfica dels anys deu i vint, alhora que document identificador de l'existència d'Estvdio- destaquem ara i en primer lloc les monografies sobre figures senyeres de les lletres catalanes: Anselm Turmeda, segons el repàs establert en quatre lliuraments editorials per Agustín Calvet (1903-1967) i d'ordre bio-bibliogràfic i crític, cronològic, històrico-filosòfic i espiritual i descriptiu de la seva obra²8; un estudi de José Casadesús (1865-1940) sobre l'Ars Magna lul-liana que, segurament, suscità un quasi immediat «Ramón Llull, valor universal» signat per Miguel Ferrá (1885-1947), que debat sobre les diverses lectures d'una figura i una obra que -«Como en su esfera el buen Cervantes...»- ha estat «... objeto de toda suerte de interpretaciones mezquinas», «... todo menos lo que fue esencialmente por encima de toda otra cosa: un generoso utopista y un místico excelso de alma ardiente.» $(E, 1917,53: 177)^{29}$; i, ja contemporàniament, Àngel Guimerà qui és abordat per Ambrosio Carrión (18881973) com a instaurador del primer teatre literari en català davant una tradició inexistent $\mathrm{i}$, alhora, com a animador d'una resposta del públic català que no sembla disposat a acudir a altres propostes teatrals posteriors que cal entendre com a coetànies al moment d'escriptura d'aquelles pàgines ${ }^{30}$.

És a partir d'aquests elements que ens plantegem una certa consideració sobre el posicionament literari d'Estvdio i de la seva redacció. Elements que van de la reconeixença d'uns clàssics a l'atenció per un passat gloriós modernament revisitat -Llull o Turmeda i Olwer-, l'arrencada i impuls de les lletres coetànies s'albiren amb desajustos. En una ressenya citada al final del primer punt, Jacint Verdaguer és vist com un puntal, tal i com ara s'ha retratat Àngel Guimerà. Però en l'atenció a les lletres més properes, sembla haver un cert regust de dubte. Això s'intueix en els judicis d'Ambrosio Carrión sobre un teatre necessàriament post-guimeranià que no funciona i també en l'asseveració següent:

La literatura catalana, poderosa y rica, está en su primer período. Por lo tanto no puede ofrecer los frutos que otras dieron, después de una larga época de formación, después de los clásicos y hasta de la decadencia. El público mismo que acepta estas obras [acostumbrado a los manjares fuertes], viniendo de literaturas extrañas, las rechaza cuando nuestros autores se empeñan en ofrecérselas. Parece decirles, que aún no ha llegado el tiempo y que se malogran por un esfuerzo prematuro $(E, 1918,62: 257)$.

\footnotetext{
d'Estudis Catalans, Anuari MCMXIII-XIV. Any V», E, 1917, 51: 529-530; F. de A. R., «José P. Gómez, Ortografía ideal. Tratado de Reforma ortográfica de la lengua castellana y de Fonografía comparada», E, 1917, 51: 613-614; F. de A. R., «Z. García Villada, Boletín de historiografía española en 1916», E, 1917, 52: 158-160.

28 A. Calvet, «Fray Anselmo Turmeda», E, 1914, 13:2-30; 1914, 14: 177-198; 1914, 15: 339$373 ; 1914,16: 1-38$.

29 J. Casadesús, «El Arte Magna de Raimundo Lulio», E, 1917, 50: 175-206; M. Ferrá, «Ramón Llull, valor universal», E, 1917, 53: 178-188.

30 A. Carrión, «El teatro de Guimerá. Ensayo crítico», E, 1918, 62: 225-257.
} 
Aquests judicis, explicitats des dels anys deu endavant, situen la revista tant contra la consagració modernista com sobre la substitució noucentista. I això és doblement susceptible d'atenció perquè, recordem-ho, SEE com a aglutinadora d'un perfil d'intel-lectuals, els mateixos intel-lectuals i aquest òrgan d'expressió se'ns havien presentat sota la qualificació de noucentistes. D'una banda i en primer lloc, aquest posicionament de previsible desconsideració del Modernisme es contradiu si anem al component literari català traduït al castellà -aquestes traduccions, en una secció de poesia quasi fixa en els números de la revista, allà on aparegueren textos lírics de les més variades literatures i no fou la més abundant la catalana-, on ens trobem amb sis composicions de Joan Maragall (trads. de M. [Matilde Ras?], de M. R. [Matilde Ras] i del Dr. José Gálvez, s.f.) i dues de Víctor Català (trads. de M. R. [Matilde Ras]) ${ }^{31}$; és aquesta una mostra de particular devocionari modernista que, en el primer cas, acorda amb el general respecte a la figura de l'autor del «Cant espiritual» - «... el inolvidable poeta Maragall» $(E, 1918,62: 257)$, fins i tot per Ambrosio Carrión en l'esmentat article sobre Guimerà i que, com resta comentat, opinava el que opinava del teatre modernista- i, en el segon cas, a la personal relació de Matilde Ras (1881-1969) amb Caterina Albert i Paradís, escriptora predilecta a qui també dedicà un relat propi ${ }^{32}$, i germana d'Aurelio Ras (n. 1881), membre destacat de la redacció d'Estvdio. D'una altra banda i en segon lloc, el que hauria d'ésser lògica mostra de gust literàriament noucentista no destaca en la tria de textos traduïts; i, a més i almenys, el nom d'Eugeni d'Ors únicament ens apareix com a signatari del manifest amb motiu de la Gran Guerra, abans recordat, i en una dedicatòria de Manuel de Montoliu en un article sobre Frederic Mistral amb motiu de la seva mort l'any 1914, mentre que un perfil de Xènius, amb la transcripció d'alguns textos seus, només s'incorpora l'últim any de la revista ${ }^{33}$.

$\mathrm{Si}$ al final dels apartats anteriors hem escrit que aquells continguts de la revista, que abreujadament hem resumit, poden veure's ratificats i ampliats en el material bibliogràfic ressenyat, això ho repetim aquí, amb la doble expectativa que la seva lectura podria oferir un ventall més ampli que notifiqui els criteris literaris d'Estvdio. Així i del que a peu de pàgina s'ordena, afrontem que quan es ressenya una obra sobre Jacint Verdaguer, s'assumeix en el poeta «... uno de los pocos valores positivos de circulación mundial.» $(E, 1914,13$ : 149), s'esperona a la consecució d'una bibliografia crítica i també que s'acari la seva biografia com «... un tema secular de investigación» $(E, 1916,44: 371)$; es recupera l'obra crítica de Joan Sardà, malgrat el segell del temps passat, prova de «... la penetración honda del crítico catalán, la exuberante riqueza de ideas y su forma atildad y serena» $(E, 1914,17: 358)$; s'atén producció castellana del costumista menorquí Àngel Ruiz i Pablo; o se celebren personalitat i obra de

31 J. Maragall, «En una casa nueva», E, 1913, 4: 51; «El almendro», «Después de la tempestad», $E, 1914,17$ : 334-335; «La noche de la Purísima», $E, 1914,36: 432$; «Fin de año», 48: 384; «La vaca ciega», $E, 1920,88: 83$; Víctor Catalá, «Los árboles viejos (siglo XVIII)», E, 1915, 30: 436; «Cар у сuа», $E, 1920,92: 238-240$.

${ }_{32}$ M. Ras, «La Muerte», E, 1913, 12: 446-451.

33 M. de Montoliu, «Mistral, el clásico moderno», E, 1914, 17: 246-271; s.f., «Ecos y notas», E, 1920, 96: 546-547. 
Pompeu Gener ${ }^{34}$. Això d'una banda, mentre que, paral.lelament, es presenta un poemari de Ramón D. Perés, on es critiquen els seus signes de líric modernista i, a més, en un espectre o «... época de verdadera crisis literaria» $(E, 1917,60$ : 525); i, si més ben mirades seran les quotes de Modernisme quan es ressenyi La Mare-Balena de Víctor Català, potser serà perquè signa Matilde Ras, ja mencionada com a devota de l'autora de l'Escala i bona coneixedora de la seva obra ${ }^{35}$. Hi ha, doncs, una reconeixença bàsica a favor del pilars literaris vuit-centistes que sembla trontollar a mida que ens situem en el trànsit finisecular. Sensació de preferible mirada enrere que s'accentua amb la desatenció a la creació estèticament més coetània. No es tracta tan sols que puguem trobar aquí o allà rebuigs a l'art contemporani -Matilde Ras, advocada dels modernistes propis, menysprea el cubisme, és cert que plàstic, com a «... última manifestación del Simbolismo enfermizo, es un desequilibrio, un error, cuyo ideal está formado de obscuridad y de confusión» $(E, 1918,69: 508)^{36}$-, potser amb algun advertiment sobre producció estrangera coetània com ara en la ressenya sobre l'estudi de Joan Pérez Jorba a propòsit de Pierre Albert Birot i el nunisme poètic ${ }^{37}$; és que, a més, no hi ha cap ressenya de l'evident triomf noucentista ni de les inicials senyals avantguardistes. De les lletres coetànies únicament s'atenen títols menors amb variats deutes estètics: narracions de Joan Santamaría Monné amb el referent de Poe, un poemari de Ferran Soldevila que recupera accents de Ronsard o l'aplec més verista de Josep Granger; hel-lenisme en les poesies de Trinitat Catasús i, si es vol, homerisme i referències a les traduccions catalanes prèvies en la ressenya a la versió castellana dels Himnes Homèrics feta pel catedràtic de la Universitat de Barcelona José Banqué y Faliu ${ }^{38}$. Però res d'això ens instal.la de manera literàriament plena ni en el Noucentisme ni en el present cultural que s'atribueix a la redacció i als col-laboradors d'Estvdio. Potser perquè la revista només era subsidiàriament literària. En tot cas, les seves signatures, pel seu perfil intel-lectual, eren ben coetànies. No obstant això i com a lectors i lectores, fins i tot en la seva funció d'antòlegs i de crítics, estaven ancorats en un temps literari assumit com a base històrica que s'imposava sobre la consciència de crisi artística que creixeria cap al període d'entreguerres. Amb tot i

${ }^{34}$ M. de M., «Robert Dubois, Bibliografía de Jacinto Verdaguer», E, 1914, 13: 149-150; F. de A. R., «Juan Sardá, Obras escogidas», E, 1914, 17: 357-358; M. M., «A. Ruiz Pablo, Clara sombra», E, 1915, 30: 524-525; M. M., «Valerio Serra y Boldú, Mossèn Jacint Verdaguer. Recorts dels set anys darrers de sa vida, seguits de una impressió sobre la causa dels seus infortunis», E, 1916, 44: 371; F. de A. R., «Pompeyo Gener, El intelecto helénico. La poesía. El arte dramático. La filosofía», E, 1919, 76: 139-140.

35 M. F., «Ramón D. Perés, La Madre Tierra», E, 1917, 60: 525-526; M. R., «Víctor Català, La Mare-Balena», E, 1920, 93: 507-508.

36 M. R., «Joan Sachs, La pintura francesa moderna hasta el cubismo», E, 1918, 69: 506-508.

37 A. M. G., «J. Pérez Jorba, Pierre Albert Birot», E, 1920, 93: 508-509.

38 N., «José Banqué y Faliu, Himnos Homéricos, vertidos directa y literalmente del griego por vez primera a la prosa castellana», E, 1914, 17: 353-357; L. L., «Joan Santamaría Monné, Narracions extraordinàries», E, 1915, 31: 134; M. M., «Fernando Soldevila, Poema de l'amor perdut», E, 1916, 45: 551; M. M., «Trinidad Catasús, De l'hort i de la costa», E, 1916, 45: 551552; M. M., «Josep Granger, Nous versos del mar», E, 1916, 45: 552. 
malgrat la susdita consciència de crisi, aquell cicle donarà uns resultats magníficament creatius que la revista no notificà.

VI. Aquest és, en qualsevol cas, un llindar que anima a endinsar-se entre les pàgines d'Estvdio, una publicació que cercà la modernització espanyola i catalana des d'uns criteris de grup conscient de la seva identitat cultural nacional, projectada per via de l'expressió castellana. Quan arribà el moment del comiat editorial, imposat per «la adversidad de las circunstancias», elegiran la paraula lul-liana i les parèmies del Llibre de mil proverbis per fer una particular selecció, amb transcripció en català i en castellà $i$, apel-lant a la transmissió de valors, poder-se acollir en el missatge del Beat mallorquí en el moment del silenciament:

Brindamos los pensamientos de Ramón Llull a la meditación de nuestros lectores. En las veladas de diciembre, cuando el espíritu se reconcentra en el hogar y en la familia, el Libro de mil proverbios puede ser un amigo cariñoso e inimitable, un rector de nuestra vida.

Nosotros ponemos las páginas maravillosas en manos de nuestros hijos. Y seguimos leyendo: Aprén de caylar en aquell qui parla. (Aprende de callar en el que habla). Obedientes a la voz de aquella mente escrutadora, profunda, seguimos leyendo y callamos $(E, 1920,96: 550)^{39}$.

\section{BIBLIOGRAFÍA}

Cerdà, J. (2000) «Eugenio D’Ors y Portugal», Actas del Congreso Internacional de Historia y Cultura en la Frontera - ler. Encuentro de Lusitanistas Españoles, J. M. Carrasco González, M. ${ }^{\mathrm{a}}$ J. Fernández García, M. ${ }^{\mathrm{a}}$ L. T. Madeira Leal (eds.), Cáceres, Universidad de Extremadura, pp. 525-541.

Harrington, T. S. (2002) «El Cercle Maristany i la interpenetretació dels sistemes literaris de la Península Ibèrica, Europa i Amèrica», Revista de Catalunya, 175, juliol/agost, pp. 107-127.

Harrington, T. S. (2003) «Álvaro Cunqueiro, Pascoaes y la editorial Apolo de Barcelona», Álvaro Cunqueiro e as amizades catalanas. Actas, J. Cerdà, V. Martínez-Gil, R. R. Vega (eds.), Sada - A Coruña, Ediciós do Castro, pp. 165-183.

Madrenas Tinoco, D. + Navas Sánchez-Élez, M. V. + Ribera Llopis, J. M. (2007-2008) «Dos escritoras del novecientos: Matilde Ras y Rosa M. Arquimbau», Revista de Lenguas y Literaturas Catalana, Gallega y Vasca, UNED, vol. 13, pp. 111-129.

Navas Sánches-Élez, M. V. (2011) «Estvdio (1913-1920): las letras portuguesas en una revista catalana de expresión castellana», Interacciones entre las literaturas ibéricas, F. Lafarga, L. Pergenaute \& E. Gallèn (eds.), Bern, Meter Lang, vol. 3, pp. 314-329.

39 «Ecos y Notas. Despedida», E, 1920, 96: 549-550. 
Ribera, J. M. (2007) Projecció i recepció hispanes de Caterina Albert i Paradís, Víctor Català, i de la seva obra, Girona, CCG Edicions.

Sellés i Quintana, M. (2002) Una aproximació a la història de la Societat d'Estudis Econòmics, Barcelona, PAM. 